\title{
ENGLISH INFLECTIONAL ERRORS MADE BY INDONESIAN DEAF PEOPLE IN WRITING COMPOSITION
}

\author{
Suwandi, Deliana, Desri Maria Sumbayak \\ Universitas Sumatera Utara (USU), Medan, Indonesia \\ E-mail: suwandi3698@gmail.com
}

Received: 2020-08-31

Accepted: 2021-02-04

\begin{abstract}
This paper was conducted to describe the types of English inflectional errors found in Indonesian deaf people in writing composition, identify the sources of the errors in the use of English inflection, and to find out the percentages. The Indonesian deaf people were from Indonesian deaf community groups on Facebook, WhatsApp, and Instagram. This research used a descriptive qualitative approach by applying English inflection theory by Andrew Carstairs-McCarthy. The data collection techniques were conducted by using an online English writing test. The results showed that there were 179 errors in total in Indonesian deaf people's writings. The most found error was in Third Person Singular Present Inflection with 51 errors (28.5\%) and the least was in Present Participle Inflection with 16 errors (9\%), and the rest were 18 errors (10\%) in Preterite Inflection, 19 errors $(10.6 \%)$ in Comparative Inflection, 22 errors (12.3\%) in Superlative Inflection, 27 errors (15.1\%) in Past Participle Inflection, and 26 errors (14.5\%) in Plural Inflection. The source of error was Intralingual Error with 156 errors (87.15\%) (False Concept Hypothesized with 6 errors (3.3\%), Incomplete Application of Rules with 8 errors (4.5\%), Overgeneralization with 23 errors (12.85\%), and Ignorance of Rules Restriction with 119 errors (66.5\%)) and Interlingual Error with 23 errors (12.85\%).
\end{abstract}

Keywords: Deaf People, Error Analysis, English Inflection

\section{Introduction}

Learning needs process, especially in learning a language, whether it is our mother tongue or foreign language, like babies learning their mother tongue or people learning foreign languages. It is what happens in learning English. It needs four skills in acquiring it, listening, speaking, reading, and writing. To support the progress of the skills, pronunciation, spelling, vocabulary, and structure should be taught to the learners.

In learning language structure, the learners need to learn about morphology as the importance can be seen clearly in writing. Morphology is the study of words, how they are formed, and their relationship to other words in a language. It analyzes the structure of words and parts of words, such as roots, stems, bases, and affixes. Morphology consists of derivation and Inflection based on the process.

Carstairs-McCarthy (2002:42) states that inflection is part of morphology which is a kind of word-formation where some words (lexemes) have more than one word form, depending on the grammatical context or on choices that grammar forces us to make (for example, in nouns, between singular and plural). 
Most people have a notion that learning English morphological inflection is difficult. Besides, Prevost \& White (2000) have proven that second or foreign language learners have difficulties in the realization of inflectional morphology in second or foreign languages. That is what happens with deaf people. Since having difficulty in hearing, the language that deaf people always use in their daily activities is limited; it is usually their mother tongue, and using sign language and writing are the ways of communication instead of speaking for them. It is the reason why there is a limitation of vocabulary or words they know, mostly general or concrete ones or everything visible and sensible. Furthermore, it makes them difficult to learn second or foreign languages.

The researchers found and read in the previous studies that Indonesian deaf students struggle in formatting Indonesian and English sentences and words. Writing would be quite a difficult thing for them. Since inflection carries grammatical context depending on how a word interacts with other words in a phrase, clause, or sentence, the understanding about that would able to make them write correctly especially in formatting words. Besides that, they have difficulties in learning grammar like any other target language learners. The most common difficulty in learning grammar is English morphological inflection.

The problems will cause the presence of errors. However, it is natural to make errors when learning something because the understanding of the lesson will not be gotten if not trying to learn and making errors before. Dulay et al (1982) points out that making errors is impossible in learning a language and errors can be used as an indicator of progress and success in mastering the language. Interference of the mother tongue is a cause of errors. Moreover, the different patterns and rules in every language must be noticed by the target language learners. It becomes the reason why errors in learning the target language especially English are quite hard to avoid.

The researchers used English inflection theory proposed by Carstairs-McCarthy (2002). He simply divides English inflection into three kinds, they are Noun (Plural), Verb ( ${ }^{\text {rd }}$ Person Singular Present, Preterite, Present Participle, and Past Participle), and Adjective Inflection (Comparative and Superlative), they are seven forms in total.

\section{Literature Review}

According to Byrne (1997:1), writing is the act of forming symbols, letters, or combination of letters, related to the sound, making marks on a flat surface of some kinds, making arrangement according to certain conventions to form words and and sentences.

The result of the activity of writing is called a text. The text can be in the form of composition. According to Cambridge Dictionary (2020) composition is a short piece of writing about a particular subject, done by a student. It is also something that a person has created or written, such as a text, a work of art, or a piece of music, or the act of creating or writing something. Since writing is a complex activity, it is considered the hardest skill to be mastered. Various morphemes would be used and integrated to make good, meaningful, and grammatically correct sentences by learners.

Learning a language always involves the making of errors, especially in writing. Dulay et al (1982) conclude that error is any deviation from a selected norm of language performance, no matter what the characteristics or causes of deviation might be. This is because it is difficult to determine the nature of error classification as performance or competence. 
Corder (1981) notes that a learner's errors are significant in that they provide the researchers' evidence of how language is learned or acquired and what strategies and procedures the learners are employing in the discovery of the language.

The sources of error are divided into two, they are interlingual and intralingual (Richards, 1980).

\section{Interlingual Errors}

Interlingual errors are errors caused by interference of the learner's mother tongue or native language. Dulay et al (1982) describe that interlingual errors are similar in structure to a semantically equivalent phrase or sentence in learner's native language. Here are some examples of error produced by Indonesian speaker:

To know if there is an interlingual error and existence of similarity, the sentences in learners' target language are translated into the learners' native language. It can be seen in His sister sad and House old. The sentences are the productions of learners' native language, Indonesian. The first sentence indicates an interlingual error in adjectival phrases; the learner interferes with the native language structure. That is why they produce His sister sad instead of His sister is sad because the translation in Indonesian Kakaknya sedih shows the similarity which interferes learner's English sentence. It also happens in the second example that should be Old house. In English, it should be modifier precedes head, but in Indonesian, head precedes the modifier.

\section{Intralingual Errors}

Intralingual errors are those which reflect the general characteristics of rule learning, such as faulty generalization, incomplete application of rules, and failure to learn conditions under which rules apply. Intralingual errors can be detected based on their characteristics (Richards, 1980).

\section{a. Overgeneralization}

In simple terms, Richards (1974:175) points out that there are two reasons for overgeneralization errors: (1) the learner's creation of one deviant structure in place of two regular structures. For example, He can sings. This sentence should be: He can sing. There is an over form of a structure verb sing becomes sings. (2) The result of the target language learners' attempts to decrease or reduce their linguistic burden.

\section{b. Ignorance of Rule Restrictions}

Richards (1974) states that ignorance of rule restrictions is the inability to uphold the limits (borders) of present formations, specifically, administering rules to inappropriate situations. It involves the application of rules to context where they do not apply. It is the learners' failure to observe the restriction of existing structures. For instance, having learned the sentence structure She arrived at home yesterday which is absolutely correct; a learner may use this previously acquired grammatical rule in a new situation or he might apply it in a situation such as She has arrived at home yesterday, which is definitely wrong. Misordering can be a good example of such errors that are caused by ignorance of rule restrictions. Richards (1974) claims that these types of errors might be caused by some structure drills that combine complementary rudiments. 
English Inflectional Errors Made by Indonesian Deaf People in Writing Composition, Suwandi, Deliana, Desri Maria Sumbayak

\section{c. Incomplete Application of Rules}

According to Richards (1974), target language learners tend to apply some of the rules and continue to construct deviant forms to ease their learning. Question formation by target language learners is a good example of these types of intralingual errors, particularly misordering some items. For example, a target language learner might produce such a sentence: when you will come to the meeting? instead of when will you come to the meeting? Richards confirms this fact by revealing that many target language learners face many difficulties in formulating questions. This type of intralingual interference of errors emphasizes the systematic difficulty in particularly formulating $\mathrm{WH}$-questions. Another example is when answering or responding questions, the learners usually do not use the right form of the verb. They usually answer the questions by taking the last phrases in the questions without noticing the questions form and what kind of verb should be used, such as in Does he speak English? They may answer the question with Yes, he speak English that should be Yes, he does and answer the question What does he order? with He order to close the door that should be He orders to close the door.

\section{d. False Concepts Hypothesized}

Intralingual errors can be also resulted from the learners' faulty comprehension of rule distinctions in the target language. Al-Tamimi (2006:44) explains that this type of intralingual error is sometimes as a result of "poor gradation of teaching items". The learners might form hypotheses about some grammatical rules of the target language. For example, target language learners might interpret using the forms was or did wrongly when they think that these forms are markers of the past tenses; therefore, they produce utterances such as one day it was happened, she was finished the homework, or He is speaks English (Richards, 1971). The other examples are as in They wented to school yesterday or They did went to school yesterday, the past tense marker is more than one, it should be They went to school yesterday, and in He doesn't knows my sister that should be He doesn't know my sister.

Inflection is part of morphology which is a kind of word-formation where some words (lexemes) have more than one word form, depending on the grammatical context or on choices that grammar forces us to make (for example, in nouns, between singular and plural) (Carstairs-McCarthy, 2002:42).

Lieber (2009) states that inflection refers to word-formation that does not change category and does not create new lexemes, but rather changes the form of lexemes so that they fit into different grammatical contexts. Borjars and Buridge (2010) also state that inflection adds some functional information to the element to which it is added, but does not drastically change the meaning of the word.

Carstairs-McCarthy (2002) simply divides English inflection into three kinds, they are Noun (Plural), Verb ( $3^{\text {rd }}$ Person Singular Present, Preterite, Present Participle, and Past Participle), and Adjective Inflection (Comparative and Superlative) which there are seven types in total.

\section{Verb Inflection}

Blevins (2006) states that regular verb inflections contain three forms based on the stem. They are a form in suffix -ing functioning as a present participle and gerund, a form in suffix -ed that functions as a preterite and past participle, and a third person singular present form in suffix -s. Irregular main verbs also have stem-based forms in suffix -ing and $-s$, but have distinctive patterns of preterite and participle suppletion. 


\section{Noun Inflection}

Blevins (2006) states English nouns inflect for number, but not case or gender. Noun plurals in English can be assigned to the three broad categories. Regular plural are marked by the suffix $-s$. Besides, English contains a number of irregular formations. Some of these plurals have no suffix (having the same form with the singular form), others retain ablaut patterns, and a couple of nouns preserve the historically weak ending -en. The third class contains nouns whose plural forms have been borrowed with their singulars.

\section{Adjective Inflection}

Blevins (2006) states English adjectives are inflected in two forms in the degree of comparison. They are comparative and superlative. Most monosyllabic adjectives and many disyllabic adjectives have synthetic comparatives in -er, and superlatives in -est, as illustrated by old-older-oldest and yellow-yellower-yellowest. The majority of adjectives with two syllables, and nearly all with three or more, from analytic comparatives with more, and superlatives with most, as in foolish-more foolish-most foolish or precocious-more precocious-most precocious.

\section{Research Method}

In this research, the researchers used a descriptive qualitative design to analyze the data, in which to describe the kinds of English inflectional errors, to identify the sources of the errors, and to find out the percentages found in Indonesian deaf people in writing composition through English writing test and documentation.

The data sources of the research were Indonesian deaf people's answers on the online English writing test. The data were their English words, phrases, and sentences showing English inflectional errors.

This research was carried out for two weeks in collecting the data. The data were collected by giving Indonesian deaf people an online writing test requiring them to write and answer a text in English. The test was done online and made with Google Form, a website to make an online form. The online test was made in Indonesian to make them more familiar with and easy to answer. The online writing test consists of four types of test, they were multiple choices consisting of twenty-five questions, missing words consisting of twenty-one questions, answering question consisting seven questions, and one essay writing about their idol, role model, or someone they impress to. The test had fifty-four questions in total. The test questions were about English inflection. The first type of the test, the multiple choices test, was made to filter the eligible participants who are the ones getting fifty percents and more of the right answers or answering correctly thirteen questions and more, and the data of the research were from the rest types. The online writing test link was shared to the deaf people community group on social media, WhatsApp, Facebook, and Instagram.

The researchers applied the procedures data analysis suggested by Ellis and Barkhuizen (2005). The first step in analyzing learners' errors is identification of errors. Identification of errors is needed to compare sentences, phrases, and words produced by the learners with the correct forms in the target language based on the understanding of the theory of the research, the theory of English inflectional morphology proposed by Carstairs-McCarthy (2002). The second step in analyzing learners' errors is description of errors. The researchers described the errors based on grammatical categories of English inflection consisting of the seven types proposed by Carstairs-McCarthy (2002). The last step is called explanation. This step was concerned with establishing the source of the error, i.e. accounting for why it was 
English Inflectional Errors Made by Indonesian Deaf People in Writing Composition, Suwandi, Deliana, Desri Maria Sumbayak

made. The errors found were classified according to its sources. They were classified into interlingual and intralingual errors (overgeneralization, ignorance of rules restriction, incomplete application of rules, and false concept hypothesized) (Richards, 1980).

\section{Results and Discussion}

After reading and identifying the errors, then the researchers described the errors. The errors were described by grouping them in a more detailed classification. The total of error found in Indonesian deaf people's compositions is 179 errors with all types of inflectional error and error source. The discussion can be seen below.

\section{a. Plural Inflectional Error}

There are 26 errors or $14.5 \%$ of the total of error of Indonesian deaf people's writings with this type of error. The errors found in plural inflection are in the plural form of noun box and person as shown in the data examples below:

(1) Thereare many boxing in my house.

(2) Mr. Budi has two boxs.

(3) Thereare five persons in the group.

(4) Thereare five peoples in the group.

As can be seen in [1], the participant wrote the wrong form of the plural form of the noun box by adding the suffix -ing that should be boxes. In [2] most of the participants follow the rule by adding the suffix $-s$ to make the noun plural. They ignore that kind of noun, a noun ended by ' $x$ ' sound, the inflectional suffix $-s$ should be -es, and then the verb turns to boxes. The error was also found in writing the plural form of the noun person. In [3] most of them also follow the rule by adding the suffix $-s$ to make the noun plural. They ignore that person is an irregular noun that should be people in the plural form. Some of them added the suffix $-s$ in the plural form of the noun as in [4].

\section{b. Third Singular Present Inflectional Error}

This is the type of error found mostly in Indonesian deaf people's writings containing 51 errors or $28.5 \%$ of the total of the error. The errors found in third singular present inflection are seen in the data examples below:

(1) He like cooking and playing her cellphone.

(2) She watching movies every Sunday.

(3) My mother is a role model for me today to be a person who is not closed, and always learn new things in this world.

(4) He also got a scholarship to Rochester Institute of Technology (RIT) in America, that inspiring me to study hard

As can be seen in [1], there is an omission of the suffix $-s$ of the verb like that should be likes, the inflectional form of verb like. This kind of error in this type is found most. Meanwhile, in [2] there is wrong addition of the suffix -ing where should be the suffix $-s$ in. In [3] the participant forgot the context of the utterances that the activities are in the habit, and then it should be learns. The last data example shows that the error has the same type as in [2], adding the wrong inflectional form of the verb inspire that should be inspires, with the suffix $-s$. 


\section{c. Preterite Inflectional Error}

There are 18 errors or $10 \%$ of the total of error of Indonesian deaf people's writings with this type of error. The errors found in preterite inflection are seen in the data examples below:

(1) Yesterday I woke up early in the morning around 5 AM then as usual I pray the shubuh shalat.

(2) I study the programming.

(3) After I woke up, I studied and doing my homework.

(4) Yesterday I watching a movie on Netflix.

As can be seen in [1] and [2], the participants wrote the wrong form of the verb where there is not any inflection. The verbs should be ended with the inflectional suffix -ed to inflect the verb in preterite or past, then make them prayed and studied. Meanwhile, in [3] the participant wrote the wrong inflection of the verb do by adding the suffix -ing that should be did, parallel with the previous verb that is in past or preterite inflection. The same thing also happens in [4], the verb is ended with suffix -ing that should be watched, ended with the inflectional suffix -ed.

\section{d. Present Participle Inflectional Error}

This is the type of error found least in Indonesian deaf people's writings containing 16 errors or $9 \%$ of the total of the error. The errors found in present participle inflection are seen in the data examples below:

(1) We are plays football at present.

(2) My mother like reads a book.

(3) No doubt it that he is the man has stories to learning and inspiring.

(4) I like Steve Jobs because he works harder until makes the word of technology with great.

In [1] even though the participant right in writing the auxiliary verb are after the subject, the participant wrote the wrong inflectional form of the verb play by adding the verb with the suffix $-s$. The verb should be playing, with the suffix -ing. In [2] the verb read should be reading, with the suffix -ing because it is a gerund. The participant wrote the wrong inflectional form of the verb by adding the verb with the suffix $-s$. In [3] the participant did not know that the verb has in the relative clause that should be having, ended with the suffix -ing. In the last data example, the participant wrote the wrong inflectional form of the word make by adding the suffix $-s$. The verb should be making, with the suffix -ing, because it is preceded by a preposition.

\section{e. Past Participle Inflectional Error}

There are 27 errors or $15.1 \%$ of the total of error of Indonesian deaf people's writings this type of error. The errors found in past participle inflection are seen in the data examples below:

(1) She has watch the movie three times.

(2) I have eated the food twice.

(3) The room is cleanes by Tono every day.

(4) The room is cleaning by Tono every day. 
English Inflectional Errors Made by Indonesian Deaf People in Writing Composition, Suwandi, Deliana, Desri Maria Sumbayak

Some participants did not write the past participle inflectional form of the verb watch as can be seen in [1]. The verb should be watched after being inflected by adding the suffix -ed. In [2], the participant inflected the wrong form of the verb eat by adding the suffix -ed. The verb should be eaten, in the past participle inflectional form. On the other hand, we can see in [3] and [4], the participants inflected the wrong form of the verb clean by adding the suffix $-s$ and the suffix -ing. The verbs should be cleaned, with the suffix -ed.

\section{f. Comparative Inflectional Error}

There are 19 errors or $10.6 \%$ of the total of error of Indonesian deaf people's writings with this type of error. The errors found in comparative inflection are seen in the data examples below:

(1) This place is widing than there.

(2) Thiscat is smalled than that one.

(3) Thiscat is more small than that one.

(4) He is tallest than me.

As can be seen in [1], the participant inflected the adjective wide with the wrong suffix. The noun should be inflected with the suffix -er not -ing. In [2] the participant wrote the wrong inflectional form of the adjective small by adding the suffix -ed. The adjective should be smaller, with the suffix -er. Meanwhile, in [3], with the same sentence, the participant wrote the wrong form of the adjective by writing the paraphrase more small. The adjective should be smaller, with suffix -er and without more because it is one-syllable adjective. In the other sentence, in [4], the other participant wrote the wrong inflectional form of the verb tall by adding the suffix -est.

\section{g. Superlative Inflectional Error}

There are 22 errors or $12.3 \%$ of the total of error of Indonesian deaf people's writings with this type of error. The errors found in superlative inflection are seen in the data examples below:

(1) Mila is the most smart student in my class.

(2) Dikais the tall student in the class.

(3) Dikais the most tall student in the class.

(4) Rino is the younger child in my family.

As can be seen in [1], the participant wrote the wrong form of the adjective smart by not inflecting it and adding most. The adjective should be smartest, with the suffix -est and without most because it is a one-syllable adjective. In the other sentence, in [2], some participants wrote the wrong form of the adjective tall by not inflecting it. Meanwhile, with the same sentence, in [3], the other participant wrote the wrong form of the verb tall by adding most and not inflecting it. The verb should be tallest, with the suffix -est because it is a one-syllable adjective. In the two last data examples, the other participants wrote the wrong form of the adjective young by adding the suffix -er as in [4]. The adjective should be youngest, with the suffix -est, because it is a one-syllable adjective.

The researchers analyzed the sources of English inflectional errors from the Indonesian deaf people's writings as the explanation of the errors was found. Richard divided source of error into interlingual and intralingual errors. 


\section{Interlingual Error}

Interlingual error appears because of the role of native language or mother tongue. In this case, Bahasa Indonesia or Indonesian is the Indonesian deaf people's native language. Most of them made these errors because of imitating the native language rules by translating the utterances from their native languages to the target language.

There are 23 errors or $12.85 \%$ of the total of error of Indonesian deaf people's writings with this source of error. The errors found in this source are seen in the data examples below:

(1) My mother is a role model for me today to be a person who is not closed, and always learn new things in this world.

(2) Yesterday I woke up early in the morning around 5 AM then as usual I pray the shubuh shalat.

(3) Thereare five person in the group.

(4) Thiscat is more small than that one.

As can be seen in [1], there are errors in third person singular present. The verb should be learns, with the suffix $-s$ showing third person singular present inflection. Meanwhile, in [2] the participant did not inflect the verbs into preterite or past inflection. The verbs should be prayed, with the suffix -ed showing the preterite inflection. In [3] with another kind of error, the participant did not inflect the noun into plural inflection. The noun should be people showing the plural inflection. In [4], the participants did not inflect the adjective by writing the paraphrase more + adjective. The adjectives should be smaller showing the comparative inflection because it is a one-syllable adjective. All the errors in this type because of the participants' native language, which is Indonesian interfere in formatting their sentences. They translated the utterances in their native language into the target language. It can be seen that there are no inflections in the verbs, noun, and adjectives as in Indonesian.

\section{Intralingual Error}

Intralingual error appears mostly because learners are unable to perform good sentences in the target language because of their low understanding or competence toward the target language's rules. Sometimes they overgeneralize sentences by mixing two different rules in one utterance, ignore the restriction of rules, make the incomplete application of rules, and hypothesize the false concept.

\section{a. Overgeneralization}

There are 23 errors or $12.85 \%$ of the total of error of Indonesian deaf people's writings with this source of error. The errors found in this source are seen in the data examples below:

(1) There are five persons in the group.

(2) Mr. Budi has two boxs.

(3) She watchs movies every Sunday.

(4) I have eated the food twice.

Most of the participants overgeneralized the plural form of the noun person by adding the suffix $-s$ as can be seen in [1]. The noun should be people in the plural form because it is an irregular noun. Some participants also overgeneralized the plural form of the noun box by adding the suffix $-s$ as we can see in [2]. The noun should be boxes in the plural form, with 
the suffix $-s$ turning to -es, because the noun is ended by ' $x$ ' sound. Meanwhile, in [3] the participant overgeneralized the third singular present form of the verb watch by adding the suffix $-s$. The verb should be watches in the third person singular present inflection, with the suffix $-s$ turning to -es, because the noun is ended by ' $c h$ ' sound. In the last data example, we can see that the participant overgeneralized the past participle of the verb eat by adding the suffix -ed. The verb should be eaten, without the suffix -ed, because it is an irregular verb. It can be concluded that all the errors appear because the participants overgeneralized the nouns and verbs by writing the wrong inflectional form of them.

\section{b. Ignorance of Rule Restrictions}

This is the type of error found most in Indonesian deaf people's writings containing 119 errors or $66.5 \%$ of the total of error of Indonesian deaf people's writings. The errors found in this source are seen in the data examples below:

(1) She always fighting for the Asian American community ...

(2) He also got a scholarship to Rochester Institute of Technology (RIT) in America, that inspiring me to study hard.

(3) After I woke up, I studied and doing my homework.

(4) She is reading a book yesterday.

As can be seen in [1], the participant wrote the wrong form of the verb fight by adding the suffix -ing. The verb should be fights, with the suffix $-s$ because the context of the utterance is in the present. Meanwhile, the other participant wrote the wrong form of the verb inspire by adding the suffix -ing as we can see in [2]. The verb should be inspires, describing the phrase He also got a scholarship to Rochester Institute of Technology (RIT) in America which is a third singular person. With the other type of error as can be seen in [3], the participant wrote the wrong form of the verb do by adding the suffix -ing. The verb should be did, inflected in the preterite inflectional form, because the context of the utterance is in the past which is parallel with the previous verb, studied. With the same type of error as we can see in [4], the other participant wrote the wrong form of the verb read by writing the auxiliary verb is and inflecting the verb read into the present perfect inflectional form. The verb should be read, showing the preterite inflection. As having been discussed before, all the errors happen because of the participants ignored the restriction of rules. They failed to observe the restriction of existing structures.

\section{c. Incomplete Application of Rules}

There are 8 errors or $4.5 \%$ of the total of error of Indonesian deaf people's writings with this source of error. The errors found in this source are as can be seen in the data examples below:

(1) My mom like her cats.

(2) My mother like cooking.

(3) My mother like jogging in afternoon sunday.

(4) I study the programming.

In answering the question What does your mother like to do? in the test, some participants did errors by writing the wrong form of the verb like as can be seen in [1], [2], and [3]. The verb should be likes, with the suffix $-s$ showing the third person singular present inflection because the context of the utterance is in the present or showing 
habit and the subjects of the answers are third person singular. On the other hand, as we can see in the last data example, the other participant answered the other question What did you do yesterday? in the test by writing the wrong form of the verb study. The verb should be studied, with the suffix -ed showing the preterite inflection because the context of the question is in the past. All the errors appear because the participants, the target language learners, tend to apply some of the rules and continue to construct deviant forms to ease their learning.

\section{d. False Concepts Hypothesized}

This is the source of error found least in Indonesian deaf people's writings containing 6 errors or 3.3\% of the total of error of Indonesian deaf people's writings. The errors found in this source are seen in the data examples below:

(1) I was studied English yesterday.

(2) Because she was passed away on 2017.

(3) Thereare five peoples in the group.

(4) English is more harder.

As can be seen in [1], the participant wrote the wrong form of the verb study by writing an auxiliary and main verb at once. The verb should be only studied, without the auxiliary verb was because the verb studied has already shown the preterite inflection. The same thing also appears in [2]. The other participant wrote the wrong form of the verb pass away. The verb should be only passed away, without the auxiliary verb was. There are also the other types of error, in plural and comparative inflection as we can see in [3] and [4]. The noun in [3] should be only people, without the suffix $-s$ because it has already shown the plural inflectional form of the verb person. Meanwhile, in [4], the adjective should be only harder, without the adverb more. All the errors appear because the participants gave double markers to the verbs, nouns, and adjectives as the results of the participants' or learners' faulty comprehension of rule distinctions in the target language. The learners might form hypotheses about some grammatical rules of the target language.

\section{Conclusion}

Based on the analysis of the research, the researchers conclude that the total of error found in Indonesian deaf people's compositions is 179 errors. The types of error found in Indonesian deaf people's writings from the lowest to highest are 16 errors (9\%) in Present Participle Inflection, 18 errors (10\%) in Preterite Inflection, 19 errors (10.6\%) in Comparative Inflection, 22 errors (12.3\%) in Superlative Inflection, 27 errors (15.1\%) in Past Participle Inflection, 26 errors (14.5\%) in Plural Inflection, and 51 errors $(28.5 \%)$ in Third Person Singular Present Inflection. The sources of error found in Indonesian deaf people's compositions are Intralingual Error with 156 errors (87.15\%) (False Concept Hypothesized with 6 errors (3.3\%), Incomplete Application of Rules with 8 errors (4.5\%), Overgeneralization with 23 errors (12.85\%), and Ignorance of Rules Restriction 119 errors (66.5\%)) and Interlingual Error with 23 errors (12.85\%). Ignorance of Rule Restriction is a source of error found mostly and False Concept Hypothesized found least among the Interlingual errors and all the sources of errors. 
English Inflectional Errors Made by Indonesian Deaf People in Writing Composition, Suwandi, Deliana, Desri Maria Sumbayak

\section{References}

Al-Tamimi, A. (2006). An Investigation of Interlingual and Intralingual Interference in the acquisition of English Present Tenses by Yemeni learners (Master's thesis). Penang, Malaysia: Universiti Sains Malaysia.

Blevins, J. P. (2006). English inflection and Derivation. In B. Aarts \& A. McMahon (Eds.), The Handbook of English Linguistics (pp. 506-536). Oxford: Blackwell Publishing Ltd.

Borjars, K., \& Buridge, K. (2010). Introducing English Grammar (2nd ed.). London: Hodder Education, an Hachette UK Company.

Byrne. (1997). Teaching Writing Skill. London: Longman Handbooks.

Cambridge Dictionary. (2020). Composition. Retrieved January 15, 2020 from https://dictionary.cambridge.org/dictionary/english/composition

Carstairs-McCarthy, A. (2002). An Introduction to English Morphology: Words and Their Structure. Edinburgh: Edinburgh University Press.

Corder, S. P. (1981). Error Analysis and Interlanguage. Oxford: Oxford University Press.

Dulay, H. et al. (1982). Language Two. New York: Oxford University Press.

Ellis, R. \& Barkhuizen, G. (2005). Analyzing Learner Language. Oxford: Oxford University Press.

Lieber, R. (2009). Introducing Morphology. Cambridge: Cambridge University Press.

Prevost, P., \& White, L. (2000). Missing Surface Infection or impairment in Second Language? Evidence from Tense and Agreement. Second Language Research, 16(2).

Richards, J. C. (1971). Error Analysis and Second Language Strategies. Language Sciences, 17, 12-22.

Richards, J. C. (1974/1980). Error Analysis: Perspective on Second Language Acquisition. London: Longman. 